Endocrinol. Japon. 1990, 37 (4), 555-561

\title{
Localization by Immunohistochemistry of Renal Ornithine Decarboxylase in the Mouse with and without Testosterone Treatment
}

\author{
Noriyuki KOIBUCHI ${ }^{1}$, Shigeru MATSUZAKI ${ }^{1}$, TAKako KITANI ${ }^{2}$, \\ Hitoshi FUJISAWA ${ }^{2}$ AND Mitsuo SUZUKI ${ }^{1}$
}

${ }^{1}$ Department of Physiology, Institute of Endocrinology, Gunma

University and ${ }^{2}$ First Department of Biochemistry, Asahikawa Medical College

\begin{abstract}
The immunohistochemical distribution of renal ornithine decarboxylase was studied in male mice both with and without testosterone treatment. Testosterone ( $1 \mathrm{mg}$ per mouse) induced a marked increase in ornithine decarboxylase activity of the mouse kidney, whereas no significant immunohistochemical difference was observed either in immunoreactivity or its localization. In intact male as well as androgen-treated mice dense ornithine decarboxylaseimmunoreactive cells were observed mainly in the cortex, especially many ornithine decarboxylase-immunoreactive cells were observed in the inner portion, while a much weaker immunoreactivity was observed in the medulla. The largest number of ornithine decarboxylase-immunoreactive cells seemed to be localized in the pars recta of the proximal tubule. The immunoreactivity was not detected in all the tubular cells but scattered among them. The renal corpuscles were not immunoreactive. In each ornithine decarboxylase-immunoreactive cell, the cytoplasm showed much denser immunoreactivity than the nucleus.
\end{abstract}

Ornithine decarboxylase (ODC), which catalyzes the formation of putrescine from ornithine, is the rate-limiting enzyme in the polyamine biosynthetic pathway. This enzyme is quite unique in that its activity fluctuates rapidly and greatly in response to various growth stimuli (Jänne et al., 1978). In the male mouse kidney, a very

\section{Received May 5, 1990}

All correspondence to : Dr. SHIGERU MATSUZAKI, Department of Physiology, Institute of Endocrinology, Gunma University, Maebashi 371, Japan high concentration of ODC has been found and the activity of the enzyme is highly dependent on testosterone treatment (Henningsson and Rosengren, 1975 ; Henningsson et al., 1978). However, it is rather difficult to detect ODC activity in most tissues by immunohistochemistry. Even if ODC activity is induced, the enzyme is only a small part of the cytosolic proteins. Persson et al. (1982) first reported the immunohistochemical distribution of ODC in the mouse kidney. Other histological studies report the distribution of ODC with radiolabelled difluoromethylornithine (DFMO) (Pegg et 
al., 1982; Zagon et al. 1984), which is an enzyme-activated irreversible inhibitor of ODC (Metcalf et al., 1978) and is known to bind specifically to the protein (Pritchard et al., 1981). They showed that ODC was localized mainly in the cortex of the kidney. However, the precise localization of ODCimmunoreactivity inside the cortex is not known, and the immunohistochemical demonstration was done after excess androgen treatment.

In the present series of experiments, we detected ODC-immunoreactivity before and after sc injection of testosterone with antisera raised against the ODC purified from rat liver (Kitani and Fujisawa, 1981), which is also immunoreactive with ODC of mouse kidney (Kitani and Fujisawa, 1988).

\section{Materials and Methods}

\section{Animals}

Male BALB C mice (8 weeks of age) from the Institute of Experimental Animal Research, Gunma University were used throughout the experiments. They were kept under conditions of controlled temperature $\left(25 \pm 1^{\circ} \mathrm{C}\right)$ and illumination (lights on, 0700-1900). Food and water were given ad libitum. The animals were separated in two groups as follows: Group I: one $\mathrm{mg}$ testosterone dissolved in $0.2 \mathrm{ml}$ propyleneglycol was injected sc $15 \mathrm{~h}$ before sacrifice for the ODC assay or immunohistochemistry and Group 2: the solvent was injected instead of testosterone.

\section{The ODC assay}

The mice were killed by decapitation $15 \mathrm{~h}$ after the injection. Then their kidneys were removed and homogenized in $4 \mathrm{vol}$ of $50 \mathrm{mM}$ sodium phosphate buffer ( $\mathrm{pH}$ 7.2) containing 5 $\mathrm{mM}$ dithiothreitol. The homogenates were centrifuged at $10,000 \times \mathrm{g}$ for $20 \mathrm{~min}$ and the supernatants were obtained for the ODC assay. The reaction mixture contained $100 \mu 1$ of the supernatant, $50 \mathrm{mM}$ phosphate buffer (pH 7.2), 0.5 $\mathrm{mM}$ ornithine, $1 \mathrm{mM}$ aminoguanidine, $0.05 \mathrm{mM}$ pyridoxal 5-phosphate and $0.1 \mathrm{mM}$ EDTA in a total volume of $200 \mu 1$. The incubation was

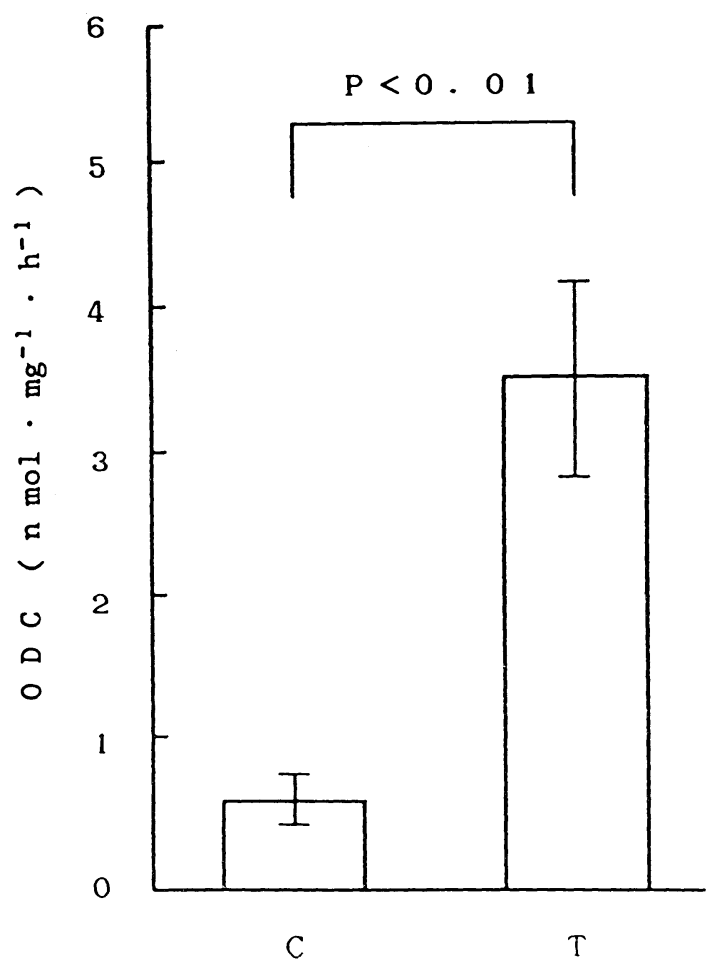

Fig. 1. Effect of testosterone on the renal ornithine decarboxylase (ODC) activity in male mice. 8-week-old male mice (BALB C strain) were given a sc injection of testosterone (1 mg per mouse) in $0.2 \mathrm{ml}$ of propyleneglycol (abbreviated " $T$ " in the figure, $N=6$ ). The same volume of the vehicle was injected into the control group (abbreviated " $\mathrm{C}$ " in the figure, $\mathrm{N}=6$ ). Each animal was killed by decapitation and ODC activity was measured. Statistical analysis was performed by Student's $t$-test.

$\Rightarrow$

Fig. 2. Comparison of immunohistochemical distribution of ornithine decarboxylase (ODC) in the mouse kidney with (2a) and without (2b) testosterone treatment. No significant difference was observed between the two groups. Note that the inner portion of the cortex (C) showed dense distribution of ODC positive cells. The outer portion of the medulla (M) showed much weaker immunoreactivity. Scale bar length : $200 \mu \mathrm{m}$. 


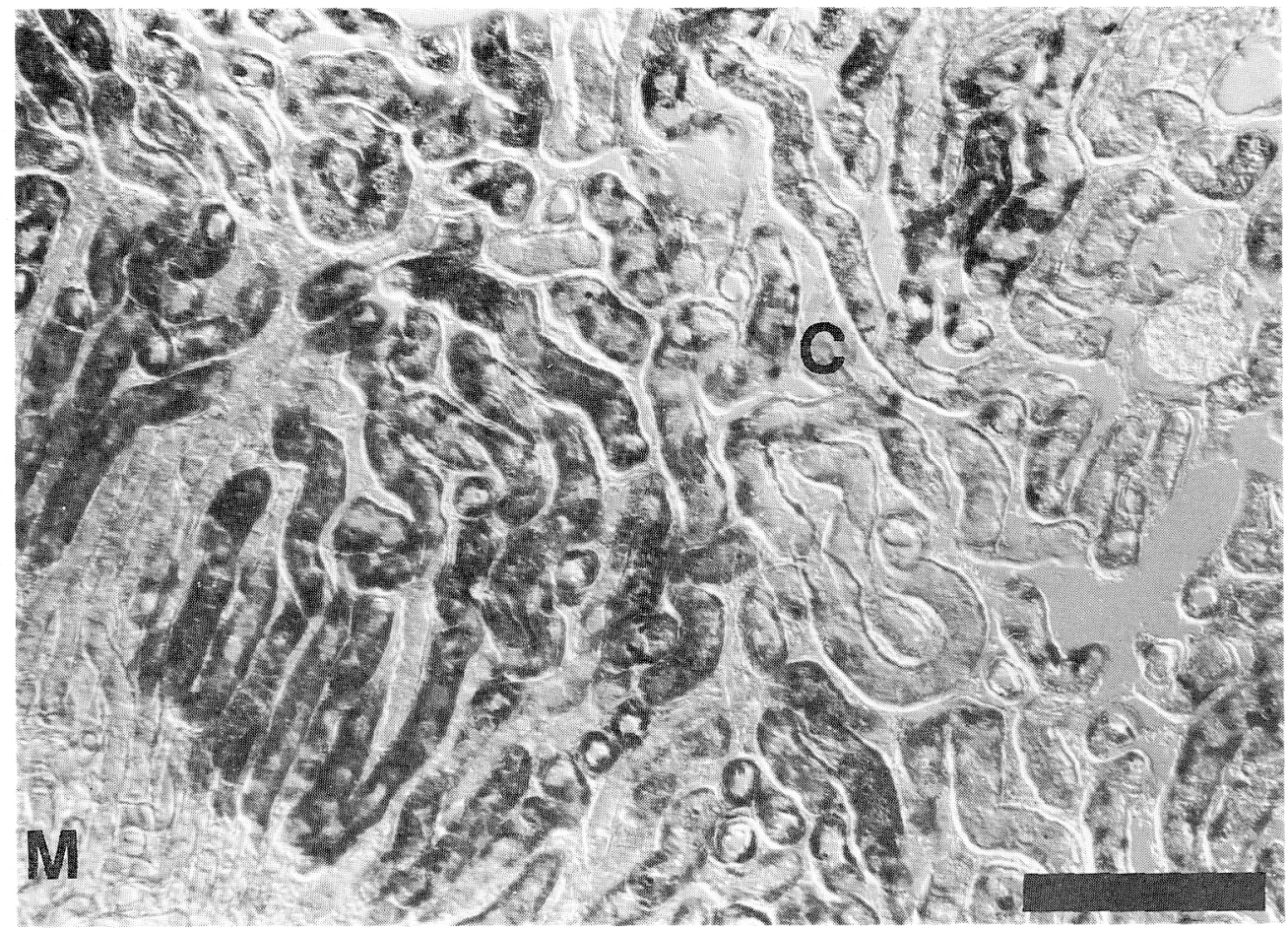

Fig. 2a i

Fig. 2b ת

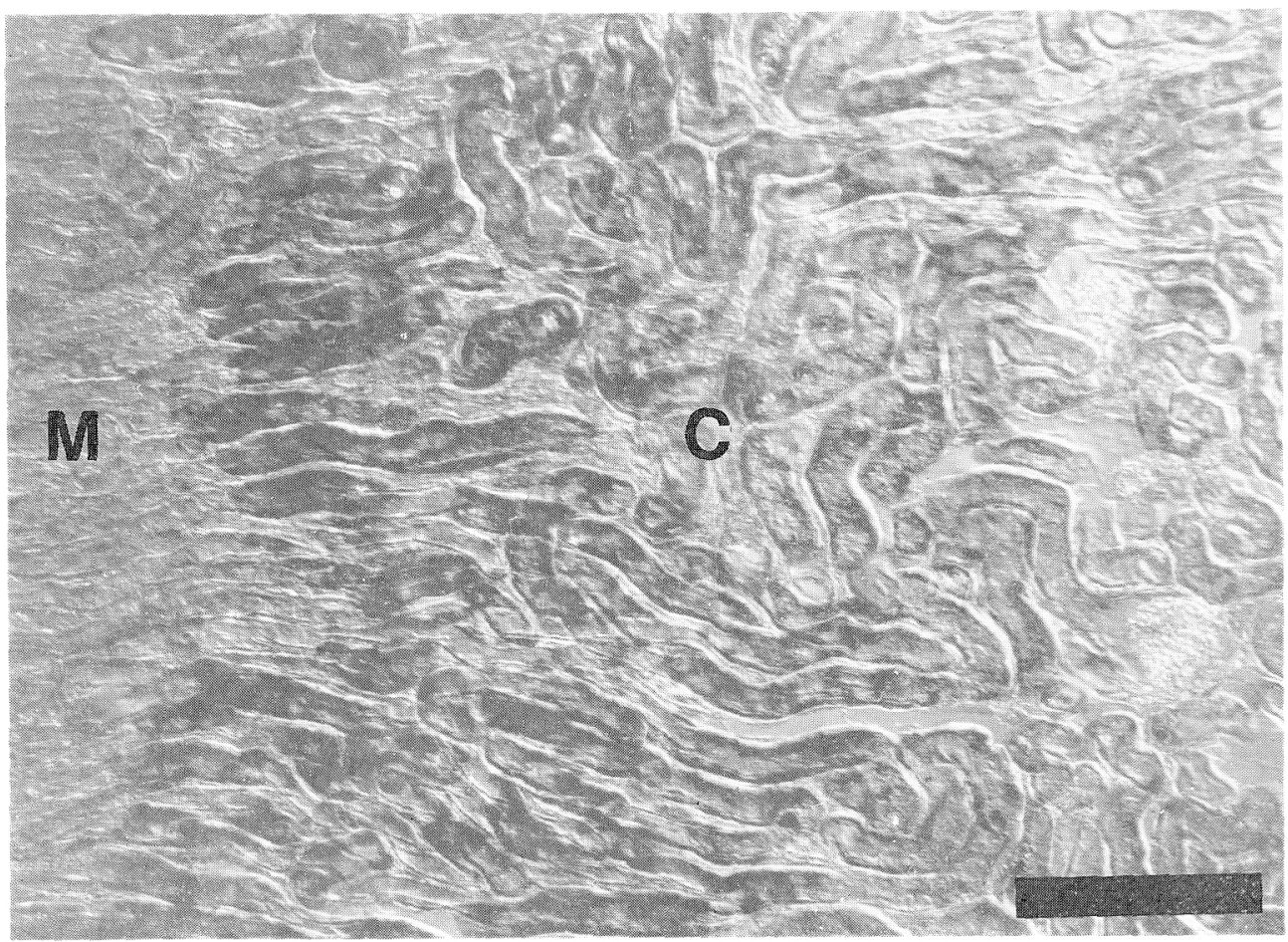


carried out at $37^{\circ} \mathrm{C}$ for $30 \mathrm{~min}$ and the reaction was terminated by adding $10 \mu 1$ of $6 \mathrm{~N}$ perchloric acid. The amounts of putrescine produced during the incubation period were measured by high-performance liquid chromatography (Matsuzaki et al., 1982). Endogenous putrescine in each sample was assayed at the same time. The enzyme activity was expressed as nmoles of putrescine produced during $1 \mathrm{~h}$ per $\mathrm{mg}$ wet tissue. The statistical analysis was performed by Student's $t$-test.

\section{Tissue preparation for immunohistochemis- try}

The mice were perfused under diethylether anesthesia through the left ventricle with cold

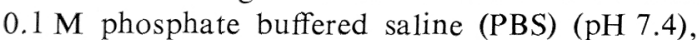
containing $4 \%$ formaldehyde and $0.2 \%$ picric acid. Then the kidneys were removed and postfixed in the same solution for 2 days at $4^{\circ} \mathrm{C}$ and $0.1 \%$ PBS containing 20\% sucrose for 2 days at $4^{\circ} \mathrm{C}$. After these treatments, $30 \mu \mathrm{m}$ frozen sections were cut on a cryostat.

\section{Immunohistochemistry}

After sectioning, these sections were rinsed in $0.1 \mathrm{M}$ PBS ( $\mathrm{pH} 7.4$ ), for $1 \mathrm{~h}$ and were processed for immunohistochemistry. The rabbit anti-ODC serum was obtained by immunization against ODC purified from rat liver (Kitani and Fujisawa, 1981), which also immunoreacts with the ODC purified from mouse kinney (Kitani and Fujisawa, 1988). The site of antigen-antibody reaction in the section was detected with rabbit peroxidase-antiperoxidase complex (PAP) purchased from Dakopatts a/s, Denmark. Methods used for immunohistochemistry were according to Yamada et al. (1987) with slight modifications. For immunohistochemistry, sections were preincubated first in $1 \% \mathrm{H}_{2} \mathrm{O}_{2}$ containing $0.1 \mathrm{M}$ PBS ( $\mathrm{pH} \mathrm{7.4),} \mathrm{for} 30 \mathrm{~min}$ and then in $0.1 \mathrm{M}$ PBS ( $\mathrm{pH} 7.4$ ), containing $1 \%$ normal horse serum and $0.4 \%$ Triton X-100 for $1 \mathrm{~h}$. These were immersed in ODC antiserum

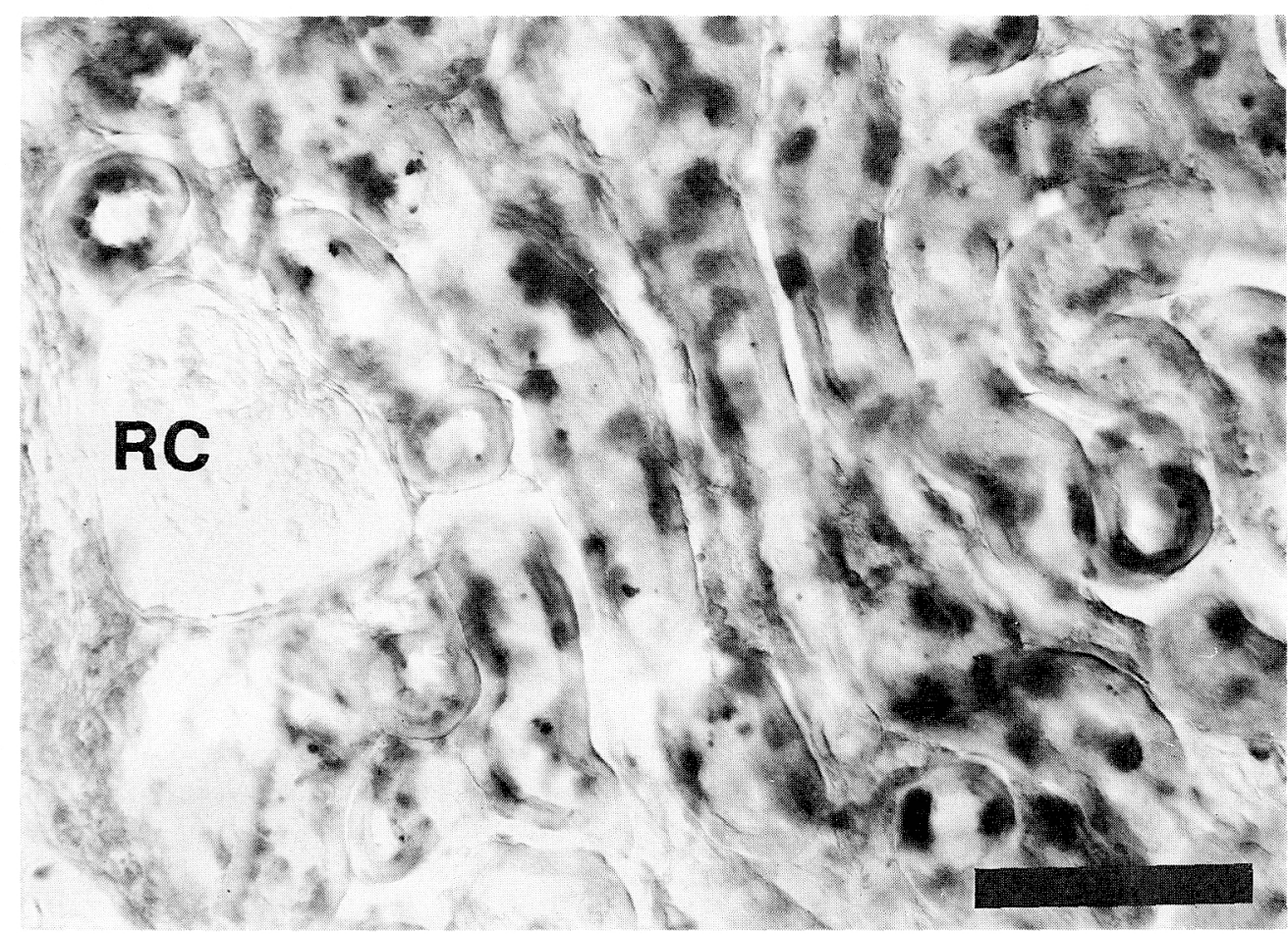

Fig. 3. Renal corpuscle (RC) showed no immunoreactivity, whereas the surrounding renal tubules showed a positive reaction. Scale bar length : $100 \mu \mathrm{m}$. 
diluted $1: 2000$ for 1 day at room temperature. Then, after further washing, the sections were incubated in goat anti-rabbit serum diluted $1: 200$ for $3 \mathrm{~h}$. These were incubated in PAP complex diluted $1: 100$ for $4 \mathrm{~h}$. The sections were rinsed in $0.05 \mathrm{M}$ Tris- $\mathrm{HCl}$ buffer, $\mathrm{pH} 7.4$. The site of ODC-immunoreactivity was expressed by incubation with $3,3^{\prime}$-diaminobenzidine tetrahydrochloride (DAB), $20 \mathrm{mg} / 100 \mathrm{ml}$ and $0.05 \%$ $\mathrm{H}_{2} \mathrm{O}_{2}$ in $0.05 \mathrm{M}$ Tris- $\mathrm{HCl}$ buffer. After staining, sections were mounted in glycerol.

For control experiments, several sections were incubated in anti-ODC serum which was inactivated by absorption with pure enzyme purified from mouse kidney (Kitani and Fujisawa, 1988).

\section{Results}

Fifteen $h$ after the injection of testosterone into the mouse, there was about a 6-fold increase in renal ODC over the control (Fig. 1). On the other hand, no significant increase in ODC-immunoreactive cells was observed and no change in their distribution was noted (Fig. 2).

In the mouse kidney, dense ODC-immunoreactive cell bodies were observed mainly in the cortex, whereas much weaker immunoreactivity was observed in the medulla (Fig. 2). Most of the immunoreactive cell bodies seemed to be localized in the renal tubule (Fig. 4). On the other hand, no positive reaction was observed in the peritubular tissue (Fig. 4). No immunoreactivity was observed in the renal corpuscle (Fig. 3). More ODC-immunoreactive cell bodies were observed in the inner portion of the cortex. In both the outer and inner portions, the ODC-immunoreactivity was

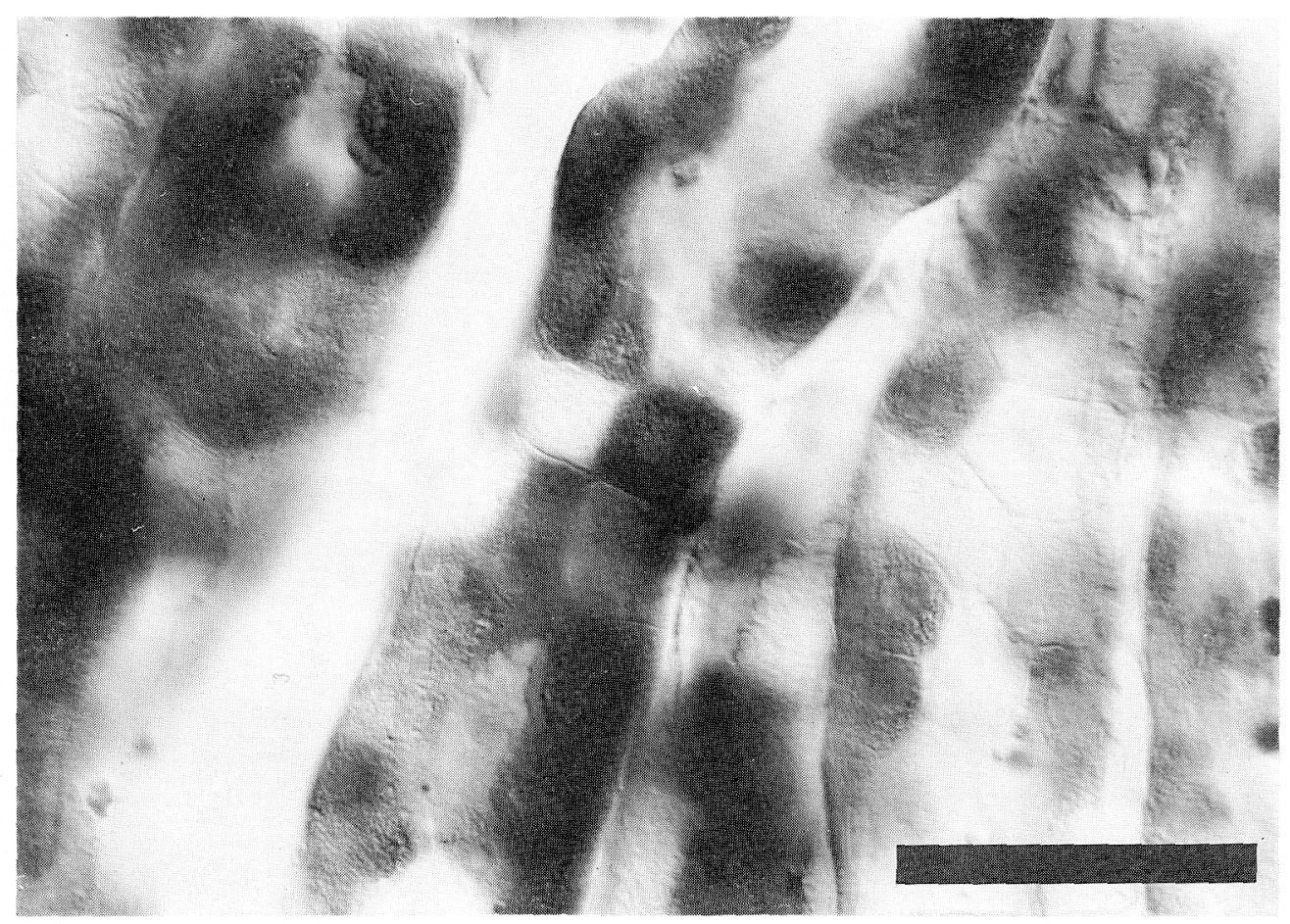

Fig. 4. Not all the cells in the renal tubule showed a positive reaction. Immunopositive cells were scattered among the immunonegative cells. No positive reaction was observed in the peritubular tissue. Scale bar length : $50 \mu \mathrm{m}$. 
not detected in all the tubular cells. The immunopositive cells were scattered among the non-immunoreactive cells (Fig. 4). In the cell, ODC-immunoreactivity was observed mainly in the cytoplasm, while only weak immunoreactivity was observed in the nucleus (Fig. 5). In the present series of experiments it was not established whether ODC-immunoreactive cells mainly localized in the proximal tubule or in the distal tubule. However, judging from the distribution pattern of the ODC-immunoreactive cells, these seemed to be confined mainly to the pars contorta and the pars recta of the proximal tubule. More immunoreactive cell bodies were observed in the pars recta. After the exposure of the antiserum to purified mouse kidney ODC, ODC-immunoreactivity disappeared in both testosteronetreated and non-treated groups.

\section{Discussion}

The results of the present series of experiments have shown the immunohistochemical localization of ODC in the kidney of the male mouse. It is likely that the ODC-immunoreactive cells are localized mainly in the pars contorta and the pars recta of the proximal tubule. In previous experiments, with antisera to mouse kidney (Persson et al., 1982) or radiolabelled DFMO (Pegg et al., 1982; Zagon et al., 1984), histological localization of ODC in the mouse kidney has been reported. All these studies were done, however, after inducing ODC activity by administering excess doses of testosterone. After androgen administration, the activity of ODC in the mouse kidney increases markedly (Henningsson et

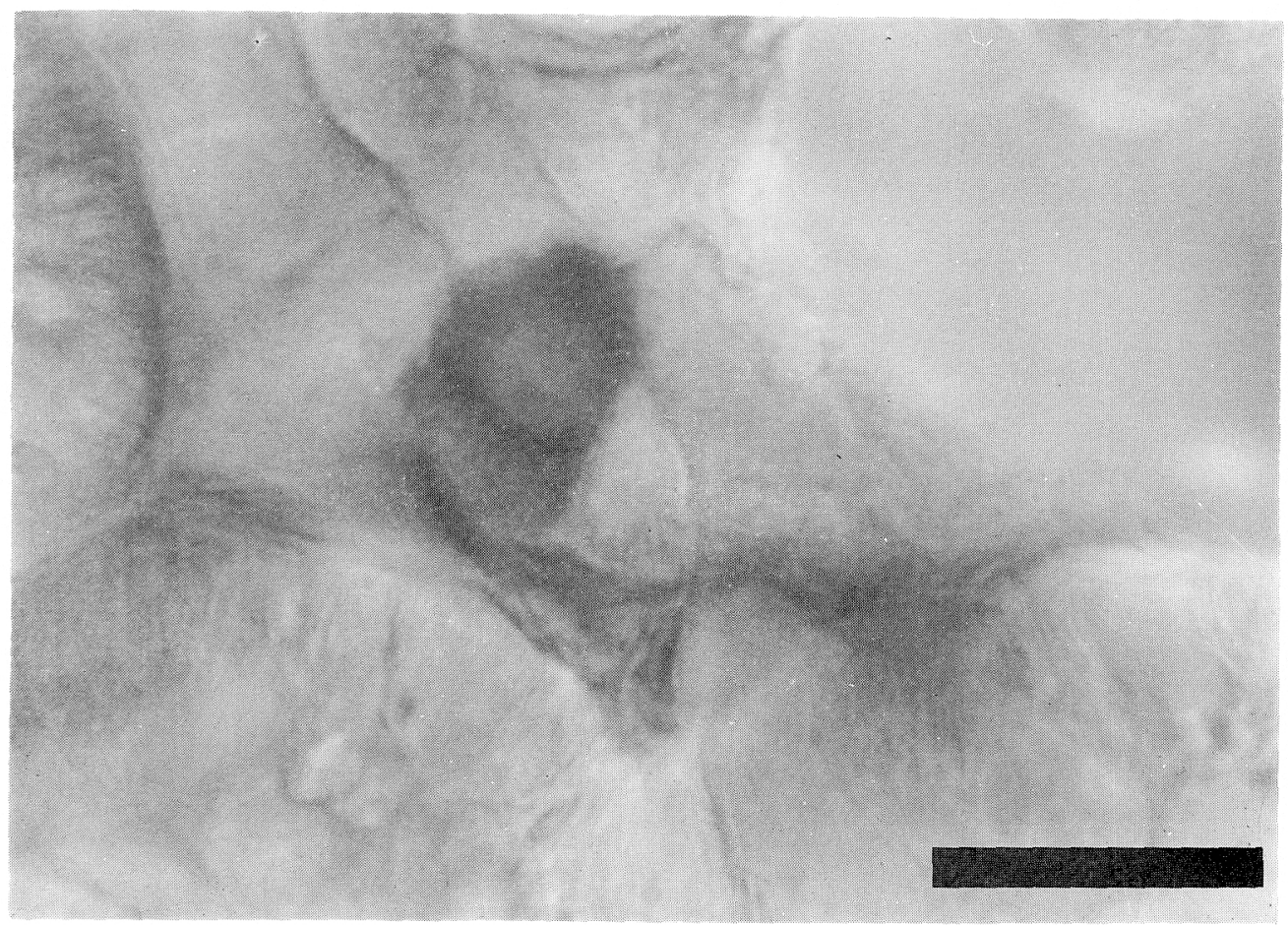

Fig. 5. In each ODC-immunoreactive cell, the cytoplasm showed more intense immunoreactivity than the nucleus. Scale bar length: $20 \mu \mathrm{m}$. 
al., 1978). After hyperinduction of ODC, the localization of immunoreactive ODC might not be the same as that in the normal male mouse. Moreover, the precise distribution of ODC has not been demonstrated. We herein confirm that the localization of ODC-immunoreactivity was not different in normal male mice from that in testosterone-treated ones.

ODC is generally considered to be a cytosolic enzyme (Jänne et al., 1987). However, an autoradiographic study with radiolabelled DFMO (Zagon et al., 1984) indicated that ODC is localized in the nucleus as well as in the cytoplasma. Although DFMO binds specifically to ODC purified electrophoretically from the mouse kidney (Pritchard et al., 1981), histological specificity of the autoradiographic localized material remains controversial (Zagon et al., 1984). The present series of experiment with a specific antibody to ODC have revealed that ODC is localized mainly in the cytoplasm.

\section{Acknowledgements}

The authors wish to thank Dr. K. Ozawa and Dr. Sakai, Department of Morphology and Dr. K. Fujikura, Department of Comparative Endocrinology, Institute of Endocrinology, Gunma University, for their technical assistance in photomicrography.

\section{References}

Henningsson S. and E. Rosengren (1975). Biosynthesis of histamine and putrescine in mice during postnatal development and its hormone dependence. J. Physiol. (London) 245, 467-79. Henningsson S. Persson L. and E. Rosengren (1978). Polyamines and nucleic acids in the mouse kidney induced to growth by testosterone propionate. Acta Physiol. Scand. 102,
385-93.

Jänne J., H. Pösö and A. Raina (1978). Polyamines in rapid growth and cancer. Biochim. Biophys. Acta. 473, 241-93.

Kitani T. and H. Fujisawa (1981). Purification and properties of ornithine decarboxylase from rat liver. J. Biol. Chem. 258, 235-39.

Kitani T. and H. Fujisawa (1988). Molecular properties of ornithine decarboxylase from mouse kidney: detailed comparison with those of the enzyme from rat liver. J. Biochem. (Tokyo) 103), 547-553.

Matsuzaki S., K. Hamana, K. Imai and K. Matsuura (1982). Occurrence in high concentrations of $\mathrm{N}^{1}$-acetylspermidine and symhomospermidine in the hamster epididymis. Biochem. Biophys. Res. Commun. 107, 307-13.

Metcalf B. W., P. Bey, C. Danzin, M. J. Jung, P. Casara and J. P. Vevert (1978). Catalytic irreversible inhibition of mammalian ornithine decarboxylase (E. C. 4.1.1.17) by substrate and product analogues. J. Am. Chem. Soc. 100, 2551-53.

Pegg A. E., J. E. Seely and I. S. Zagon (1982) Autoradiographic identification of ornithine decarboxylase in mouse kidney by means of $\alpha-\left[5-{ }^{14} \mathrm{C}\right]$ difluoromethylornithine. Science 217, 68-70.

Persson L., E. Rosengren and F. Sundler (1982). Localization of ornithine decarboxylase by immunocytochemistry. Biochem. Biophys. Res. Commun. 104, 1196-201.

Pritchard M. L., J. E. Seely, H. Pösö, L. S. Jefferson and A. E. Pegg (1981). Binding of radioactive $\alpha$-difluoromethylornithine to rat liver ornithine decarboxylase. Biochem. Biophys. Res. Commun. 100, 1597-603.

Yamada H., S. Mori, S. Ueda, M. Kawata and Y. Sano (1987). Improvement of technique of immunohistochemical demonstration of bioactive substances in the central nervous system. Acta Histochem. Cytochem. 20, 62937.

Zagon I. S., P. J. McLaughlin, J. E. Seely, G. W. Hoeksema and A. E. Pegg (1984). Autoradiographic localization of ornithine decarboxylase in mouse kidney by use of radiolabeled $\alpha$-difluoromethylornithine. Cell Tissue Res. 235, 371-77. 